\title{
O PLANEJAMENTO TERRITORIAL NO BRASIL NOS ANOS \\ 1990: AS AÇÕES DAS EMPRESAS GLOBAIS DE CONSULTORIA (O CASO DA BOOZ-ALLEN \& HAMILTON)
}

\author{
ADRIANA MARIA BERNARDES DA SILVA ${ }^{1}$ \\ Departamento de Geografia, Instituto de Geociências, Unicamp \\ ALCIDES MANZONI NETO² $\square$ \\ Mestrando do Programa de Pós-Graduação em Geografia, Instituto de \\ Geociências, Unicamp
}

\section{Introdução}

No Brasil, a década de 1990 impulsionou uma vigorosa transformação do território. A adoção de um quadro normativo em consonância com a globalização autorizou a abertura, sem precedentes, da economia nacional. Ora, tal contexto parece implantar o "governo de uma ordem privada" alavancado por grandes empresas que conduzem, com o apoio do Estado, um projeto de uso corporativo do território. ${ }^{3}$ Acelerada e seletivamente são superpostos no território brasileiro mosaicos de especializações produtivas entrevistos nas novas formas industriais, agrícolas e de serviços que redefinem as escalas regionais pretéritas e conformam os espaços da globalização (SANTOS, 1994a).

Durante a década das políticas de desestatização e da tentativa de conformar um planejamento territorial mais sistematizado, tanto a base material dos lugares quanto as ações organizativas se subordinaram violentamente ao poder econômico e político de um seleto grupo de grandes empresas. As grandes organizações desenharam suas políticas

\footnotetext{
${ }^{1}$ Bolsista de Produtividade em Pesquisa do CNPq.

${ }^{2}$ Bolsista da Fundação de Amparo à Pesquisa do Estado de São Paulo (Fapesp).

${ }^{3}$ Ressaltamos, então, que a categoria de análise não é o território (em si), mas sim o uso do território (SANTOS, 1994c), pois importa estarmos munidos, a um só tempo, para refletir o impacto das novas ações sobre a materialidade e os condicionantes sociais recriados a partir dessa mesma materialidade.

${ }^{4} \mathrm{O}$ poder econômico de uma empresa seria "dado exclusivamente pela menor ou maior capacidade de combinar eficazmente os fatores da produção de que dispõe, de um ponto 
territoriais valendo-se de modelos de gestão difundidos mundialmente por novos atores sociais, especialmente aqueles vinculados ao ideário da ordem global. Entre esses atores destacamos as agências internacionais, as empresas de consultoria e marketing, determinadas organizações não governamentais, entre outros.

Um balanço prévio da conjuntura dos anos 1990 permite reconhecer que a tônica do debate político foi articulada e arrastada segundo a ótica do mercado e da competitividade em detrimento da construção de um pacto social abrangente para conduzir o desenvolvimento ou o futuro do território nacional (FURTADO, 2000; SANTOS, 2000). Por isso acreditamos que urge abrir uma ampla agenda de pesquisa a respeito dos novos atores, das estratégias e dos instrumentos que arquitetam e que viabilizam a política territorial das grandes empresas no atual período.

Ora, neste contexto de globalização destacam-se as informações econômicas produzidas e difundidas pelas grandes empresas de consultoria. "Pacotes de assessoria" tornaram-se verdadeiros insumos (e verdadeira panaceia) de competitividade, de busca por fluidez, pois passaram a conferir às empresas que os utilizam um poder econômico e político ainda maior (GOE, 1996:25). O ajuste das grandes organizações às crises sucessivas tem sido feito, em grande medida, nos escritórios das agências de consultoria. Estas têm por objetivo reduzir custos, melhorar métodos de controle, aperfeiçoar problemas de recursos humanos e conhecer os locais mais produtivos. E, ainda que estejam em fase de crescimento econômico, as organizações dependem do apoio de informações para resolverem questões urgentes e complexas, porque em um ambiente acirrado de competição é necessário manter posição e ampliar as forças de mercado (BORDELEAU, 1986). Daí Gallouj (1994:34) afirmar que a crescente demanda por consultoria é determinada pelas características da economia contemporânea: "complexidade, incerteza e riscos". Wood (1996:661) sintetiza, por sua vez, que "a adaptação de modelos espaciais de produção e comercialização, sob a pressão da

de vista eminentemente técnico, o que concerne a produção imediata". O poder político de uma empresa, por sua vez, seria dado pela "capacidade de modificar, no momento hábil, regras do jogo econômico, em sua própria área de atividade e em função de seus interesses emergentes", em particular aqueles relacionados à velocidade da acumulação (SANTOS, 1994a:63). Segundo Karpik (1978:46), as grandes organizações agem hoje como "governos privados". Para o autor, esses "governos privados estendem-se nos territórios onde as empresas operam, formando poderosos campos de competitividade". 
competição internacional, desregulação ou privatização, dominam grande parte dos esforços administrativos".

As intencionalidades que regem as ações das grandes empresas de consultoria estão fundamentadas, portanto, na racionalidade da globalização. Chamemos essas ações, por seu conteúdo hierárquico, de verticalidades (SANTOS, 1994a, 1996, 2000). São novos sistemas de ações que auxiliam as estratégias técnicas e políticas das grandes empresas e daqueles Estados empenhados em promover políticas de cunho neoliberal.

$\mathrm{Na}$ medida em que o Estado brasileiro incorporou a gestão empresarial como modelo de conduta, um grupo seleto de empresas de consultoria foi convocado a dar legitimidade à implantação seletiva da modernização, despontando como porta-voz das aspirações do mercado. Poder-se-ia afirmar que, no caso brasileiro, esses atores passaram a interferir ativamente nos processos em curso que redefinem os usos e a regulação do território. O processo de privatização no Brasil é, nesse sentido, emblemático. As grandes empresas de consultoria foram convocadas pelo Banco Nacional de Desenvolvimento Econômico e Social (BNDES) para conferir racionalidade técnica e credibilidade, no âmbito dos mercados internacionais, ao programa de privatizações, transformando-o em oportunidades de negócios nas redes globais. Aprofundou-se sobremaneira a internacionalização da economia e do território nacional na década de 1990 com as privatizações, aquisições e fusões estrategicamente auxiliadas por empresas globais de consultoria (SILVA, 2002).

Também é emblemático o contorno normativo e técnico que norteou o planejamento territorial conduzido por esses agentes da globalização. Como assinalou Becker (1991:54), "o contexto de fragilização da União e a diluição dos interesses gerais se revela no acirramento da competição pelo controle do território, e na nova forma de sua gestão". Implementou-se no território brasileiro uma "regulação delegada" aos cuidados, entre outros, das empresas globais de consultoria; trata-se de uma "regulação cujas ordens se situam fora de sua competência territorial e deixam pequena margem para a escolha de caminhos suscetíveis de atribuir, de dentro, um destino ao próprio território nacional" (SANTOS e SILVEIRA, 2001:268). Araújo (2000) problematiza que o país vive, como consequência, um momento de "desintegração competitiva".

Vejamos alguns aspectos desse movimento revelados por nossas pesquisas. 


\section{Consultoria corporativa, círculos de informação e unicidade técnica}

Em face da diversidade de empresas produtoras de informação, destacam-se as de consultoria, especializadas em comercializar aquilo que, parafraseando Santos (1989), poderia ser denominado "mercadoria organizacional". Lojkine (1995) menciona os seguintes exemplos de "informação mercadoria": (a) mercado de patentes científicas; (b) mercado de softwares; (c) mercado da mídia; (d) mercado de obras de arte, entre outros. Incluiríamos aqui o mercado de modelos de gestão para a economia e o território, também conhecidos como teorias do planejamento estratégico.

A grande empresa de consultoria comercializa, pois, uma informação sigilosa que, em última instância, é também uma importante manifestação do poder contemporâneo (as informações que circulam em grande quantidade são banais e de fácil acesso). $\mathrm{O}$ segredo das missões de conselho é um dado estratégico fundamental para o denominado bom desempenho das ações, repercutindo em ganhos maiores de competitividade e, assim, ampliando o poder político das grandes empresas. ${ }^{5}$

No ramo da consultoria coexistem inúmeros tipos de funções especializadas, envolvendo empresas globais e algumas poucas empresas nacionais de grande porte. São empresas que buscam minimizar os riscos que ameaçam a geopolítica das firmas globais, na medida em que auxiliam as organizações a regular problemas políticos e racionalizar as operações técnicas. ${ }^{6}$

${ }^{5}$ Conforme Mostafa (1994), a informação ao assumir a condição de mercadoria na sociedade capitalista conforma uma contradição, pois se transforma em não informação: (a) pela ausência da informação (ou seu sigilo) nos mercados que então passam a negociálas; (b) pelo bombardeamento de informações através dos meios de comunicação de massa. Para o autor, a liberdade de informações consiste numa forte ideologia contemporânea, pois "por mais que se aumente a quantidade de informações, isso não elimina a diferença qualitativa de informações veiculadas, tanto na ponta da produção de informações, quanto na ponta do consumo".

${ }^{6}$ A consultoria de negócios é um ramo de atividade que surgiu, timidamente, no início do século XX, nos EUA, juntamente com o embrião das corporações. As empresas norteamericanas, que passaram a adotar os modelos tayloristas da administração científica, tornaram, pouco a pouco, seus quadros gerenciais profissionalizados e treinados. $\mathrm{O}$ forte crescimento das empresas de consultoria dos países anglo-saxões, no pós-guerra, por sua vez, insere-se nos processos complexos da globalização. 
Para Stern e Tutoy (1995), as grandes empresas industriais, de serviços e financeiras são "sofisticadas" pelo uso que fazem da consultoria, na medida em que as corporações passaram a falar a mesma linguagem dos consultores, tirando o máximo proveito de suas intervenções. Wood (1996:661) pondera que "em termos geográficos os consultores são, primeiramente, agentes de mudanças globais (...) promovendo internacionalmente técnicas de gestão para acelerar o ritmo da reestruturação através da dispersão dos administradores corporativos".

As empresas de consultoria desenvolvem, na verdade, uma linguagem universal de negócios, que vimos nomeando, como propôs Santos (1996), de unicidade técnica, com vistas, entre outros objetivos, a autorizar a vigorosa aceleração dos fluxos intra e interfirmas nos circuitos superiores da economia global. A atividade de consultoria, por conseguinte, é sequiosa de insumos técnicos, científicos, organizacionais, bem como é dependente de informações estratégicas (políticas) e de um meio geográfico denso em objetos informacionais. Todo esse conjunto de fatores inclui a consultoria (tal como a definimos aqui) entre os elementos constitutivos dos espaços da globalização. Estamos falando dos setores mais corporativos da economia, justamente aqueles que se manifestam nas dinâmicas territoriais de forma vertical, isto é, através de redes.

É necessário, pois, problematizar as ações desses novos atores. Conforme assinalou Ribeiro (2000), nos países periféricos ocorre hoje uma perda da expressividade da esfera política instituída e a eclosão de novas instituições sociais significativas do tecido social construído pela atual modernidade (aí incluídas as firmas de assessoria e consultoria). Nas palavras da autora, "esta perda implica no predomínio do pensamento econômico sobre o político e o social e, portanto, numa aguda racionalização das relações sociais e societais".

A partir da década de 1970, um grupo de empresas de consultoria constituiu poderosas redes planetárias de informações e incluiu nessa nova arquitetura, de forma subordinada, regiões de países periféricos como o Brasil. Essas são faces de uma nova divisão territorial do trabalho assentada na variável informação, de onde vislumbramos novos esquemas hierárquicos de controle dos territórios periféricos.

Compreender a produção e o controle dos fluxos ou círculos de informação corporativa é muito importante, pois são eles que irão atingir, verticalmente, o arranjo horizontal das regiões por meio do impacto de ações organizacionais, modificando o conteúdo da rede urbana e criando novas tensões socioespaciais. 
Entre as dez principais consultorias em gestão no mundo, todas têm escritórios na cidade de São Paulo, existentes, com pequenas exceções, desde o início da década de 1970. Tais unidades instaladas na cidade de São Paulo exercem a função de comando das ações para o território brasileiro. Vale ressaltar, por conseguinte, que São Paulo agora comanda o território também por acolher, produzir, coordenar e distribuir informações corporativas não encontradas, com a mesma densidade, em outros lugares da rede urbana nacional. É como centro informacional que essa cidade se renova e mantém sua primazia, sua onipresença no território nacional (SANTOS, 1994b; SILVA, 2002).

O mapa a seguir evidencia a densidade informacional do estado de São Paulo; caso detalhássemos a distribuição dos escritórios nessa unidade da Federação, encontraríamos a cidade de São Paulo como principal abrigo para as empresas de consultoria.

Concentração dos escritórios das empresas de Consultoria no Brasil (2005)

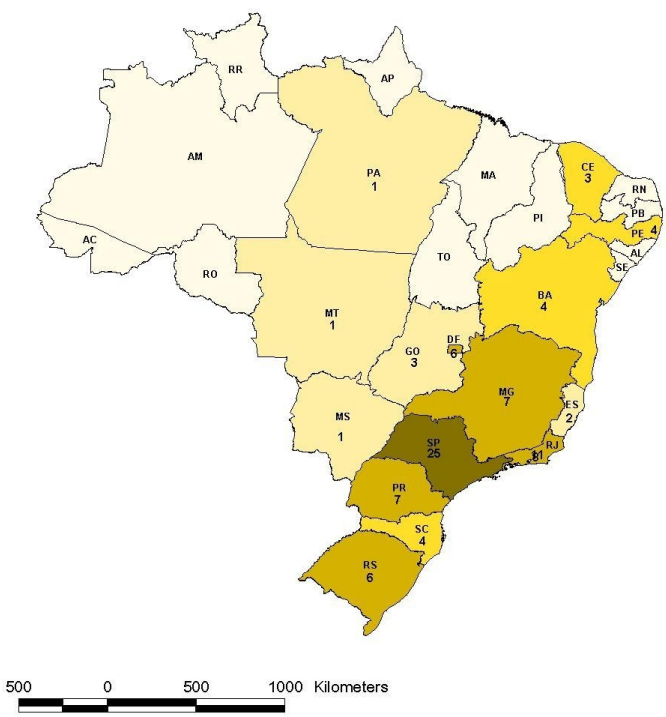

SP e RJ : Emst \& Young, KPMG, PriceWatherHouse, Trevisan Boucinhas, Bozz Allen, Accenture, Deloitte e Mackinsey SC : KPMG, PriceWatherHouse, Trevisan e Deloitte RS : Ernst \& Young, KPMG, PriceWatherHouse Trevisan e Deloitte

PR : Ernst \& Young, KPMG, PriceWatherHouse, Trevisan, Boucinhas e Deloitte

PE : Ernst \& Young. PriceWatherHouse, Trevisan e Deloitte

MG : Ernst \& Young, KPMG, PriceWatherHouse. Trevisan, Boucinhas e Deloitte

DF : KPMG, PriceWatherHouse, Trevisan, Boucinhas, Accenture e Deloitte

BA : Ernst \& Young. PriceWatherHouse, Trevisan e Deloitte

CE : Ernst \& Young, Trevisan e Deloitte

ES : PriceWatherHouse eTrevisan

GO : Trevisan e Boucinhas

MT, MS e PA: Trevisan

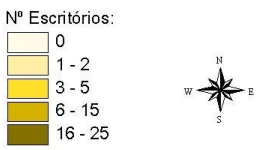


Destacam-se, desde os anos 1980, as redes de informação articuladas no território brasileiro pelo grupo de empresas conhecido como Big Five; são empresas que controlam grande parte do mercado mundial e latino-americano de consultoria e auditoria: Price Waterhouse Coopers, Andersen Consulting (Accenture), KPMG, Ernst \& Young e Delloitte Touche. ${ }^{7}$ Todavia, outras importantes empresas transnacionais da consultoria em gestão merecem destaque por também atuarem nas últimas décadas em amplos processos envolvendo: (a) reestruturação empresarial; (b) inovações em tecnologias da informação; (c) privatizações e planejamento territorial. Além das Big Five, constam, por exemplo, as empresas McKinsey \& Co. e Booz-Allen \& Hamilton, as quais representariam outro polo do mercado de consultoria: as firmas especializadas em estratégia (DONADONE, 2001).

Do conjunto supracitado de empresas, vimos valorizando em nossas investigações as ações da Booz-Allen \& Hamilton no Estado brasileiro. A empresa esteve entre os principais agentes responsáveis pelo novo arranjo do planejamento territorial, na década de 1990, para estimular a integração competitiva entre as regiões, visando ampliar, portanto, a inserção do país nas redes da globalização.

A Booz-Allen \& Hamilton é uma empresa privada, com sede em McLean (Virgínia), nos Estados Unidos, e se encontra atualmente entre as maiores firmas de consultoria em estratégia e gestão do mundo, fornecendo serviços às principais corporações transnacionais e a governos. ${ }^{8}$ No ano fiscal de 2002 (encerrado em 31 de março de 2002), a empresa registrou

${ }^{7}$ Até meados da década de 1960, tais empresas atuavam apenas na área de auditoria. Somente na década seguinte se voltaram para o setor da consultoria.

${ }^{8}$ A história da empresa se inicia em 1935, quando Carl Hamilton junta-se à firma, a qual se torna, em 1936, uma nova sociedade, a Booz, Fry, Allen, \& Hamilton. Nesse momento, incluem entre seus clientes a Container Corp. of America, a US Gypsum e a American Red Cross. Em 1940, a empresa fornece serviços ao governo a pedido do secretário da Marinha norte-americana, com o objetivo de prepará-la para a guerra. Em 1942, Fry deixa a sociedade após desentendimento sobre o futuro do trabalho com o governo, e a firma torna-se, em 1943, Booz Allen Hamilton. Em 1944, a firma presta serviços de consultoria às empresas que se preparavam para o trabalho civil e para a esperada "explosão da reconstrução" do pós-guerra. Já em 1947, obtém o primeiro contrato com a força aérea norte-americana, levando a acordos em inteligência eletrônica e com os principais fabricantes de aviões. Nesse mesmo ano, ultrapassa-se o número de cem funcionários e o faturamento da empresa atinge US\$ 2 milhões. Ao longo da década de 1950, a empresa estabelece seu primeiro estudo fora dos Estados Unidos, com a reorganização dos registros de posse de terra nas Filipinas (1953). 
US\$ 2,1 bilhões de vendas anuais, e houve uma expansão no quadro de funcionários, passando para mais de 11 mil consultores sediados em escritórios distribuídos, sobretudo, nos Estados Unidos e na Europa. No território brasileiro, a empresa mantém escritórios nas metrópoles de São Paulo e Rio de Janeiro.

Suas principais áreas de especialização são: (a) estratégia; (b) organização e liderança estratégicas; (c) operações; (d) tecnologia da informação; (e) gerenciamento de tecnologia; (f) prestação de serviços para o setor público.

\section{Distribuição dos escritórios da Booz Allen \& Hamilton no mundo}
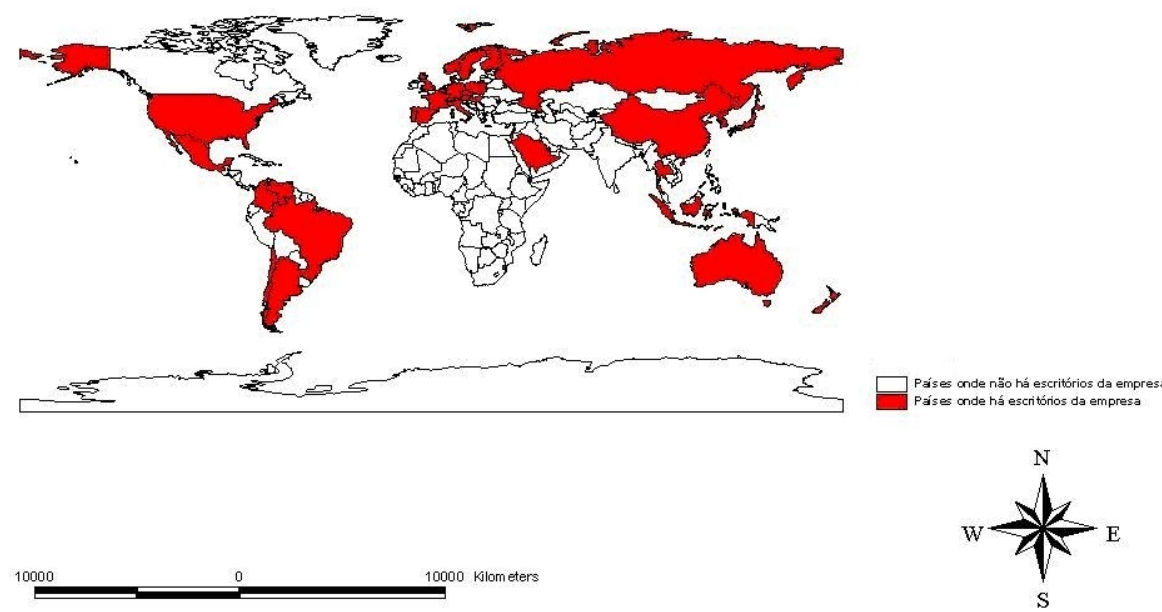

Figura 2: Distribuição dos escritórios da Booz-Allen \& Hamilton no mundo em 2004 Fonte: Elaborado pelos autores a partir de dados obtidos em $<$ www.boozallen.com $>$.

Chama a atenção, observando o mapa, a ausência de escritórios da Booz-Allen \& Hamilton no continente africano, ${ }^{9}$ enquanto há uma

${ }^{9}$ Isso não significa que os territórios africanos estejam "livres" da ação desses atores, como bem salientou Meneses (2004). A pesquisadora apresenta uma rica e crítica reflexão 
distribuição nas regiões estratégicas do Terceiro Mundo, como América Latina e Ásia. Ressalta-se o papel que esses sistemas de objetos, verdadeiras "tecnoestruturas" nas palavras de Ianni (2000), desempenham na conformação de uma série de ações, como as que conduziram as privatizações (Silva, 2002).

O escritório da Booz-Allen \& Hamilton no Brasil sempre atuou como estrategista dos interesses norte-americanos. Na década de 1940, a divulgação do estudo que ficou conhecido como Relatório Booz-Allen provocou enorme polêmica devido a suas considerações sobre o setor siderúrgico no Brasil. Nesse relatório, afirmava-se que o país apresentava condiçõ̃es de implantar a siderurgia, mas não possuía, entre outros elementos, escala de produção. Dessa forma, a consultoria se opôs à implantação da Companhia Siderúrgica Nacional (CSN) durante o governo de Getúlio Vargas. Ora, a empresa se colocou contra um projeto de fortalecimento de um setor estratégico da indústria nacional, que constava nos planos de ampliação do parque produtivo do país e consequente ampliação da integração do mercado interno. ${ }^{10}$

Desde então, houve diversas participações da firma no planejamento regional no Brasil. Segundo Donadone (2001:20), ao longo do século XX os consultores tornaram-se "elos de ligação institucional responsáveis pela transferência do conhecimento organizacional do setor privado para o setor público".

Mais recentemente, a Booz-Allen participou ativamente do Programa Nacional de Desnacionalização (PND), fornecendo consultoria à privatização das empresas CST (Cia. Siderúrgica de Tubarão) em 1990, Açominas (Aço Minas Gerais S.A.) em 1992, Ciquine (Cia. Petroquímica) em 1992, Banco Meridional S.A. em 1995 e Banespa (Banco do Estado de São Paulo) em 1998. Nota-se que cinquenta anos depois a empresa volta a interferir no processo de industrialização, novamente quanto à questão da siderurgia nacional, agora dando auxílio à privatização de uma grande empresa do setor.

No final de 1997, a consultora constitui, com a Bechtel International Inc. e o Banco ABN Amro, o Consórcio Brasiliana, que ficou

sobre o papel hegemônico dos consultores que trabalham para agências internacionais e conduzem políticas sociais em Moçambique. Podemos ainda mencionar as empresas Price Waterhouse Coopers, Andersen Consulting (Accenture), KPMG, que, entre outras, mantêm redes de escritórios em vários territórios africanos.

${ }^{10}$ Segundo Luiz Ablas, em entrevista concedida a Alcides Manzoni Neto em novembro de 2004. 
responsável por dar suporte metodológico ao Programa "Avança Brasill", no $\mathrm{PPA}^{11}$ 2000-2003. Difundiu-se, com maior profundidade, a noção de "eixos de integração e desenvolvimento" para subsidiar a distribuição dos investimentos públicos e/ou privados. O governo federal buscava uma nova orientação para o planejamento regional e, ao mesmo tempo, alimentava e legitimava um processo de regulação e uso do território segundo o receituário neoliberal. Como veremos, os eixos de desenvolvimento privilegiaram setores (transportes, energia e telecomunicações) e apenas as "regiões ganhadoras", esta verdadeira concepção do "pensamento único".

\section{Um projeto "importado" para reorganizar o território brasileiro: algumas reflexões a mais sobre os PPAs e a atuação do Consórcio Brasiliana}

A partir da segunda metade da década de 1990, ao término do primeiro mandato de Fernando Henrique Cardoso (1995-1998), buscou-se elaborar uma teoria e uma metodologia próprias de um conceito definidor de Plano Plurianual ou de uma modalidade de planejamento de médio prazo, visto que até então os dois primeiros PPÃs careciam desse embasamento $^{12}$ (GARCIA, 2000; GALVÂO e BRANDÃO, 2003).

Haviam se passado quase dez anos desde o estabelecimento do artigo 165, $\S 9^{\circ}$ da Constituição Federal, o que suscita a dúvida do porquê de uma longa espera para definir os contornos de uma questão de grande relevância. A explicação pode ser buscada na forma como os sucessivos governos da década em questão compreendiam o planejamento público, identificando-o apenas como planejamento econômico. Acreditava-se que, uma vez inexistente a estabilidade econômica, não haveria como se pensar a longo prazo, nem como planejar ações para o país como um todo,

${ }^{11}$ Segundo estipulou-se na Constituição de 1988, em seu artigo 165, o Plano Plurianual (PPA) visava dar uma maior coerência às ações governamentais ao longo do tempo, além de organizar consistentemente as intervenções parlamentares, subordinando "a seus propósitos todas as iniciativas que não tenham sido inicialmente previstas" (GARCIA, 2000:6). Esse novo instrumento deveria abranger o período compreendido entre o segundo ano de um mandato presidencial e o primeiro ano do mandato subsequente.

${ }^{12}$ Isso se deu devido a um certo descaso com o planejamento governamental por parte do Poder Executivo, na medida em que a Constituição de 1988 determinava em seu artigo 165 que uma lei complementar estabeleceria as normas para "a vigência, os prazos, a elaboração e a organização do Plano Plurianual, da Lei de Diretrizes Orçamentárias e da Lei Orçamentária Anual” ( $\left(9^{\circ}\right)$. 
manifestando uma visão unidimensional que a administração pública possui da realidade e, consequentemente, do território.

Em 14 de outubro de 1997, houve uma reação positiva do Poder Executivo, que finalmente decidiu investir no sistema do planejamento público. Com a emissão da Portaria Interministerial $\mathrm{n}^{\mathbf{0}} 270$, constituiu-se um grupo de trabalho integrado por representantes dos Ministérios do Planejamento e Orçamento (SPA, SOF, Sest, Ipea, IBGE) e da Fazenda (STN, SFC, SRF, Bacen), do Tribunal de Contas da União, do Confaz, do Ibam, da Abop $^{13}$ e da Associação dos Profissionais em Finanças Públicas, cujo objetivo era elaborar em sessenta dias o projeto de lei complementar de que trata o artigo 165, $\S 9^{\circ}$ da Constituição Federal. O trabalho deveria abarcar a perspectiva do Poder Executivo, mas considerando as formulações e os aportes dos projetos de lei e substitutivos originados no Parlamento.

Uma vez concluídos os trabalhos em 17 de dezembro de 1997, o grupo, denominado Grupo de Trabalho Interministerial (GTI), apresentou sua proposta. Destacamos, em linhas gerais, que esse estudo buscou integrar o planejamento com a programação orçamentária pelo aperfeiçoamento das definições e conceituações das principais categorias programáticas dos três instrumentos: O Plano Plurianual (PPA), a Lei de Diretrizes Orçamentárias (LDO) e o Orçamento Geral da União (OGU). Segundo a proposta, o planejamento deveria ser visto com um "processo permanente que obedecerá a princípios técnicos e terá em vista o desenvolvimento econômico e social e a contínua melhoria das condições de vida da população" (GARCIA, 2000:20), compreendendo a elaboração de um diagnóstico da situação existente, com a identificação e a seleção de problemas para o enfrentamento prioritário, dando grande destaque à constituição de programas. Considerou-se, ainda, que as propostas eram condizentes com as formulações mais avançadas na área do planejamento estratégico público (GARCIA, 2000). ${ }^{14}$

${ }^{13}$ SPA: Secretaria de Planejamento e Avaliação; SOF: Secretaria de Orçamento Federal; Sest: Secretaria de Controle de Empresas Estatais; Ipea: Instituto de Pesquisa Econômica Aplicada; IBGE: Instituto Brasileiro de Geografia e Estatística; STN: Secretaria do Tesouro Nacional; SFC: Secretaria Federal de Controle Interno; SRF: Secretaria da Receita Federal; Bacen: Banco Central do Brasil; Confaz: Conselho de Política Fazendária; Ibam: Instituto Brasileiro de Administração Municipal; Abop: Associação Brasileira de Orçamento Público.

${ }^{14}$ A assinatura, em 28 de outubro, do Decreto $n^{\circ} 2.829$ - que estabelece normas para a elaboração e gestão do Plano Plurianual e dos Orçamentos da União - e a emissão, pelo Ministério do Planejamento e Orçamento, da Portaria n 117 de 12/11/98 (substituída pela 
Apesar do esforço realizado pelo grupo, acreditamos que o sistema de planejamento público continuava imbricado a um discurso cientificista, que por sua vez não corresponde a uma real politização do planejamento governamental. A questão ainda carecia de participação democrática. $\mathrm{O}$ debate permanecia circunscrito aos "cientistas", ou seja, "aqueles que têm o poder para legitimar uma ação", articulando um discurso competente, como trata Chaui (1982). ${ }^{15}$ Permanecia assim uma dicotomização no planejamento governamental entre o plano técnico e o político.

Desse modo, uma vez estabelecidos os parâmetros técnicos do planejamento, o estudo que veio a ser realizado imediatamente ao término do elaborado pelo GTI poderia trazer a contribuição de deslocar a discussão para o âmbito político, discutindo-se as atribuições de um verdadeiro projeto para o país. Mas a forma como o BNDES conduziu a questão e os pressupostos adotados pelo Estudo dos Eixos pareciam apontar para um presente contínuo.

Concomitantemente à elaboração teórica do GTI - frisa-se: um grupo de pesquisadores brasileiros ligados a diversos órgãos públicos - $\mathrm{e}$ durante a implementação do PPA 1996-1999, o Ministério do Planejamento e Orçamento (posteriormente renomeado Ministério do Planejamento, Orçamento e Gestão), juntamente com o BNDES, "constatou a necessidade de aprofundar a concepção dos Eixos de Desenvolvimento, para que fosse realizado um levantamento minucioso dos desafios e potencialidades de cada um dos eixos" (FERES, 2002:285). Para tanto, o referido Banco lançou o Edital de Licitação PBA/CN-01/97 para a realização do Estudo dos Eixos Nacionais de Integração $e$ Desenvolvimento, sob sua supervisão, o qual foi vencido pelo Consórcio Brasiliana.

Constituído pela filial brasileira de uma das maiores empresas de consultoria do mundo, a Booz-Allen \& Hamilton Consulting, pela Bechtel

Portaria do Ministério do Orçamento, Planejamento e Gestão n ${ }^{\circ} 42$ de 14/4/99, que mantém o conteúdo básico, mas ajusta alguns pontos) permitiram a alteração da classificação funcional utilizada nos orçamentos públicos, criando as subfunções e estabelecendo conceitos necessários para operacionalizar as normas do Decreto $\mathrm{n}^{\circ} 2.829$. Assim, foi estabelecido um marco na reforma do sistema de planejamento e orçamento públicos.

15 "O discurso competente é aquele que pode ser proferido, ouvido e aceito como verdadeiro ou autorizado (...) que cultua patologicamente a cientificidade (...) O discurso competente é o discurso instituído. É aquele no qual a linguagem sofre uma restrição que poderia ser assim resumida: não é qualquer um que pode dizer a qualquer outro qualquer coisa em qualquer lugar e em qualquer circunstância” (CHAUI, 1982:7). 
International Inc., que figura entre as principais empresas mundiais de construção civil, e por um grande banco internacional, o ABN Amro S.A., esse consórcio produziu, após um ano de sua constituição, um estudo denominado Identificação de Oportunidades de Investimentos Públicos e/ou Privados, conforme orientação do Edital, ficando conhecido como Estudo dos Eixos. Sua importância deve-se ao fato de ter culminado na orientação metodológica e de investimentos do Programa do segundo PPA do governo Fernando Henrique Cardoso, o "Avança Brasil” (2000-2003).

Segundo o relatório do Consórcio, o objetivo central do Estudo foi estimular o desenvolvimento da Infraestrutura Econômica (Transporte, Energia e Telecomunicações), Desenvolvimento Social (Educação, Saúde, Habitação e Saneamento), Meio Ambiente e Informação \& Conhecimento, além de contribuir para "a melhoria da competitividade sistêmica da economia". ${ }^{16}$

Assim fundamentado, o Estudo do Consórcio serviu-se da possibilidade aberta pelo Edital de aperfeiçoar os doze Eixos estabelecidos pelo Ministério do Planejamento e Orçamento. Determinou-se como primeiro passo a definição de um conceito mais abrangente de Eixo de Desenvolvimento que o utilizado anteriormente, com vistas a melhor adequá-lo ao planejamento, seguindo uma antiga orientação metodológica de J. R. Boudeville. Coube à Booz-Allen \& Hamilton do Brasil, a consultora "nacional" do Consórcio, ${ }^{17}$ desenvolver o estudo de identificação e caracterização dos Eixos Nacionais de Integração e Desenvolvimento, sob a coordenação de Luiz Ablas.

${ }^{16}$ Tal estudo apresentava como pressuposto um enfoque "holístico e geoeconômico, fundamentado no conceito de desenvolvimento sustentável, e numa abordagem que prioriza a orientação voltada ao mercado e aos negócios" (CONSÓRCIO BRASILIANA, 2000:1; grifos nossos).

${ }^{17}$ O Edital de Licitação para a contratação do Estudo exigia que houvesse no Consórcio uma empresa brasileira de consultoria, conhecedora das especificidades do território nacional. Coube à Booz-Allen \& Hamilton do Brasil cumprir esse papel. Na visão do governo federal, a Booz-Allen \& Hamilton do Brasil representava uma consultoria brasileira, conforme orientação do Edital de Licitação, pois ela seria independente dos outros escritórios no mundo, havendo somente um relacionamento funcional entre eles. Entretanto, discordamos desse posicionamento, pretensamente neutro, que afirma haver uma independência do escritório brasileiro em relação ao grupo Booz-Allen. Preferimos, no momento, problematizar que o conjunto de informações adquiridas não deixou de servir e enriquecer os bancos de dados da empresa mundial, como resultado dos círculos de cooperação estabelecidos. São questões importantes, para as quais nossas investigações buscam respostas. 
Segundo o Relatório Síntese do Estudo, o conceito de Eixo Nacional de Integração e Desenvolvimento apresentava como elemento dominante a logística de transporte de alta capacidade, tal como o adotado no Plano Plurianual 1996-1999. Porém, visando definir regiões de planejamento, foram incluídos outros "planos de análise" no âmbito econômico, social e ambiental. De tal modo, para os idealizadores do Estudo, definiu-se um conceito de Eixo que avançaria no sentido de se aproximar de um conceito de região, superando de certa forma a noção antes estabelecida e firmada somente na logística: "Eixo é um recorte espacial composto por unidades territoriais contíguas, efetuado com objetivos de planejamento, e cuja lógica está relacionada às perspectivas de integração e desenvolvimento consideradas em termos espaciais" (CONSÓRCIO BRASILIANA, 2000:14).

Ressaltamos, entretanto, que o esforço realizado pelos consultores culminou na valorização de uma abordagem tradicional do conceito de região, epistemologicamente ultrapassada. Fortaleceu-se um ponto de vista geométrico do espaço, não condizente com as novas realidades características do período atual, garantidas pelo aumento do número de eventos nos lugares.

O referido Estudo buscou "seccionar" o território nacional para identificar "as atividades dominantes" e os respectivos "aspectos sociais e ambientais" em cada um dos recortes espaciais. A visão era a de que as atividades dominantes estariam localizadas em "centros dinâmicos", apresentados com polos de infraestrutura econômica, responsáveis pelo dinamismo econômico do eixo. Uma vez identificadas tais atividades, seria possível estabelecer a dinâmica econômica de cada eixo, com a visão de que "a inserção de cada eixo no País resulta em crescente 'especialização produtiva' em torno de determinadas atividades, sendo que cada eixo desempenha um papel na divisão espacial do trabalho estabelecida no âmbito do País, o que pode conduzir a uma maior competitividade" (CONSÓRCIO BRASILIANA, 2000:34). Ou seja, além de abrir caminho para a competitividade entre os próprios eixos, demonstrava-se o objetivo de promover uma integração extravertida - com os mercados internacionais -, deixando de lado a integração do país, carente de amálgamas regionais, como confirma a crise da Federação e a guerra dos lugares (SANTOS, 2002).

Assim, delimitaram-se nove Eixos Nacionais de Integração e Desenvolvimento a partir de uma superposição dos Ecossistemas, da Malha Multimodal de Transportes, da Hierarquia Funcional de Cidades e dos Focos Dinâmicos da Economia, constituindo uma enorme redução da 
complexidade do espaço geográfico, considerando inclusive a configuração territorial como formas desprovidas de conteúdo. São eles: Eixo Rede Sudeste, Eixo Sudoeste, Eixo Sul, Eixo Transnordestino, Eixo São Francisco, Eixo Oeste, Eixo Araguaia-Tocantins, Eixo MadeiraAmazonas e Eixo Arco Norte.

\section{A elaboração do Portifólio de Investimentos: algumas observações sobre a constituição dos círculos globais de informação}

Segundo a divisão adotada para a elaboração do Estudo, coube à Bechtel realizar a proposição dos projetos, cujo resultado foi a elaboração de um Portifólio de Investimentos. A empresa é uma das maiores firmas de engenharia, construção e projetos de gerenciamento de companhias do mundo. Fundada em 1898, está hoje sediada em São Francisco, nos Estados Unidos, e contava, em 2004, com cerca de 60 mil funcionários espalhados por mais de sessenta países. ${ }^{18}$

Dessa forma, segundo a divisão entre a Booz-Allen e a Bechtel, coube à primeira definir quais seriam os problemas e quais seriam as soluções, e coube à segunda determinar como resolver os problemas. ${ }^{19}$ Nota-se como é a Política das Empresas que hoje direciona, em grande medida, o uso e a organização do território brasileiro.

Esse Portifólio de Investimentos tinha por objetivo contemplar empreendimentos estruturantes em Infraestrutura Econômica, Desenvolvimento Social, Informação \& Conhecimento e Meio Ambiente, para que houvesse maior integração entre os Eixos. A partir de tais investimentos, visava-se "promover, num horizonte de oito anos (até 2007), o desenvolvimento econômico e social do País, a melhoria da competitividade sistêmica da economia e a redução das disparidades sociais e regionais" (CONSÓRCIO BRASILIANA, 2000:208). O Estudo ressalta ainda o novo papel do Estado, um Estado mínimo (regulador), condizente com as orientações neoliberais, na condução dos investimentos: "Dado o novo papel do Estado, deseja-se que os investimentos incluídos no

${ }^{18}$ Desde 1898, a Bechtel já promoveu mais de 22 mil projetos em 140 países. Cabe ressaltar ainda que o grupo possui uma empresa no Brasil denominada BMT Bechtel Método Telecomunicações Ltda., uma joint venture com o propósito de analisar as oportunidades de crescimento do mercado de telecomunicações no país.

${ }^{19}$ Luiz Ablas, em entrevista concedida a Alcides Manzoni Neto em novembro de 2004. 
Portifólio, notadamente no campo da infraestrutura econômica, sejam atraentes à iniciativa privada". ${ }^{20}$

Baseado no conceito de Polo de Desenvolvimento (PERROUX, 1967), o Estudo identificou os "Centros Dinâmicos do país", ou seja, lugares que pudessem acolher os denominados empreendimentos estruturantes, vistos como os "empreendimentos com suficientes efeitos sinérgicos sobre a realidade do espaço em que se insere, no sentido de provocar impactos positivos sobre as possibilidades de outros novos empreendimentos" (CONSÓRCIO BRASILIANA, 2000:222). A análise desses Centros Dinâmicos revela como há uma orientação estratégica por investimentos em pontos eleitos do território, cujo potencial de inserção nos "mercados competitivos internacionais" é maior. O espaço é organizado segundo os interesses de poucos agentes, visto que na prática, como destaca Santos (2003), os tão aclamados efeitos multiplicadores, quando ocorrem, são em pequena escala.

\begin{tabular}{|c|c|c|c|}
\hline Eixo & \multicolumn{2}{|c|}{$\begin{array}{c}\text { Investimentos do } \\
\text { Portifólio }\end{array}$} & $\begin{array}{c}\text { \% Eixo no } \\
\text { PIB }\end{array}$ \\
\hline & em US\$ bilhóes & $\begin{array}{c}\text { em } \\
\mathbf{\%}\end{array}$ & $\mathbf{1 9 9 6}$ \\
\hline $\begin{array}{c}\text { Araguaia- } \\
\text { Tocantins }\end{array}$ & $23.839,80$ & 11,5 & 6,6 \\
\hline Arco Norte & $1.272,80$ & 0,6 & 0,3 \\
\hline Madeira- & $17.245,70$ & 8,3 & 3,8 \\
\hline Amazonas & $7.514,40$ & 3,6 & 2,2 \\
\hline Oeste & $66.598,30$ & 32,2 & 52,3 \\
\hline Rede Sudeste & $18.751,60$ & 9,1 & 6,1 \\
\hline São Francisco & $12.787,60$ & 6,2 & 8,4 \\
\hline Sudoeste & $25.530,30$ & 12,3 & 13,3 \\
\hline Sul & $28.075,90$ & 13,6 & 7 \\
\hline Transnordestino & $5.370,20$ & 2,6 & - \\
\hline Nacional & $\mathbf{2 0 6 . 9 8 6 , 5 0}$ & $\mathbf{1 0 0}$ & $\mathbf{1 0 0}$ \\
\hline Total Geral & \multicolumn{3}{|c}{} \\
\hline
\end{tabular}

Tabela 1: Portfólio - Distribuição Espacial dos Investimentos

Fonte: Estudo dos Eixos, Relatório Síntese, Tomo I, 2000.

Funcionalizando uma visão setorial do território nacional, o referido Estudo produziu ainda um Portifólio de Investimentos, da ordem de US\$ 207 bilhões, em que 50\% desse valor corresponderia a investimentos em projetos de Infraestrutura Econômica e cerca de $44 \%$ aos de Desenvolvimento Social, ficando o restante alocado aos demais setores: Informação \& Conhecimento e Meio Ambiente. Concebido como "um

${ }^{20}$ Luiz Ablas, idem. 
subsídio valioso ao processo de planejamento do setor público", tal Portifólio corresponderia a "uma fração relativamente reduzida do total de investimentos do País, e nem poderia ser diferente, já que o Portifólio contempla apenas investimentos estruturantes em alguns, mas não em todos os setores" (CONSÓRCIO BRASILIANA, 2000:229). Portanto, o Portifólio representou um conjunto de oportunidades de investimento para um horizonte de oito anos; já o PPA estabeleceu 365 programas para um horizonte de quatro anos, englobando todas as ações de governo e não apenas em Infraestrutura Econômica, Desenvolvimento Social, Meio Ambiente e Informação \& Conhecimento.

Para alguns pesquisadores, esse Portifólio reunia projetos que já estavam prontos; ou seja, na elaboração do documento "desengavetou-se" uma série de projetos. ${ }^{21}$ Quer dizer, o governo já vislumbrava investimentos estratégicos nas frações luminosas do território (SANTOS, 1994a), mas era necessário ter a salvaguarda de um estudo feito por uma consultoria internacional, para que houvesse maior credibilidade junto aos investidores internacionais, como ocorreu nas privatizações. Quanto à distribuição espacial dos investimentos, houve clara concentração nas áreas que já dispunham de maiores densidades técnicas e informacionais, ${ }^{22}$ pois interessava investir nos pontos que já eram competitivos (ARAÚJO, 2000).

Era preciso pensar em possíveis financiamentos para os empreendimentos; em outras palavras, era preciso projetar estrategicamente as Parcerias Público-Privadas (PPPs). Cabe ressaltar que esse Portifólio esteve à disposição de três empresas internacionais envolvidas com informações sobre a virtualidade dos lugares. Cabe, por conseguinte, ressaltar a inserção do Banco ABN Amro S.A. ${ }^{23}$ Essa instituição financeira "acabou tendo nas mãos uma série de projetos em que ela própria poderia buscar financiamentos no exterior daquilo que

${ }^{21}$ É o caso de Carlos A. Brandão, em entrevista concedida a Alcides Manzoni Neto em outubro de 2004.

${ }^{22}$ Como define Santos (1996:205), a densidade técnica "é dada pelos diversos graus de artifício"; a densidade informacional "indica o grau de exterioridade do lugar e a realização de sua propensão a entrar em relação com outros lugares, privilegiando setores e atores"; a densidade comunicacional resulta da interdependência obrigatória e da solidariedade que se dão nos lugares. Por sua vez, a densidade normativa refere-se ao conjunto de normas técnicas "responsáveis pela regulação das formas de utilização dos novos objetos no processo de trabalho" (SILVEIRA, 1999:243).

${ }^{23}$ O Banco ABN Amro é uma importante empresa global. Constituído em 1824, está presente em mais de sessenta países, tem cerca de 104 mil funcionários e movimenta aproximadamente 637,5 bilhões de euros (dado de 30 de setembro de 2004). 
interessasse a ela, na condição de um banco". ${ }^{24} \mathrm{O}$ mesmo se pode dizer das duas outras empresas envolvidas, pois uma vez responsáveis pela elaboração do Portifólio elas poderiam obter vantagens relativas no mercado, caso desejassem participar de licitações. Dessa forma, foi-lhes permitido ampliar seu conhecimento sobre o território brasileiro, assegurando-lhes aumentar seus bancos de dados estratégicos na condição de importantes mercadorias informacionais (SILVA, 2002) e possibilitando-lhes dar garantia às empresas que as contratam de manterem um uso reticular do território (SANTOS, 1996), aprofundando inclusive a já conturbada crise da Federação.

\section{Considerações finais}

Diante do quadro exposto, ponderamos que as concepções de planejamento territorial em curso se afastam de uma visão integrada do território usado. Tende-se a adotar, hoje, para o planejamento das cidades e regiões, as bases teóricas da Business Administration, aplicando ao planejamento do território tudo aquilo que é aplicado ao planejamento de uma empresa. Elabora-se para o território uma lista de ameaças, oportunidades, obstáculos, que corresponde basicamente aos mesmos estabelecidos para uma empresa.

Nesse processo, as empresas de consultoria, sobretudo transnacionais, adquirem uma força inequívoca, pois aparecem como agentes indispensáveis para a sistematização de informações sobre as virtualidades dos lugares. Ao mesmo tempo, são as grandes propagadoras de novos modelos de gestão, que muitas vezes resultam em uma visão empresarial no uso do território, sendo, por sua vez, apropriada pelo planejamento público. Como consequência, o campo do planejamento territorial encontra-se em um momento de profunda transformação em seu conteúdo e suas metodologias, o que nos faz questionar em que medida os novos preceitos adotados vão ao encontro de um pacto territorial mais justo, visto que parece cristalizar-se uma substituição do médio e do longo prazos pelas necessidades imediatas, que nem sempre coincidem com os anseios da nação.

Uma análise do estudo realizado pelo Consórcio Brasiliana impõese como etapa fundamental para a compreensão dos novos rumos adotados pelo planejamento público ao longo da década de 1990. Nota-se como as

${ }^{24}$ Como ressaltou Luiz Ablas, em entrevista concedida a Alcides Manzoni Neto em novembro de 2004. 
consultorias participam ativamente de um movimento de importação de modelos de desenvolvimento gerados nos países centrais, perpetuando uma separação histórica entre aqueles que produzem, sintetizam e disseminam o conhecimento (países centrais) e aqueles que produzem dados e informações (países periféricos) (MENESES, 2004). Ao longo desse processo, "o papel do planejamento não pode ser ocultado (...) sobretudo quando influem certas firmas consultoras, de intimidade notória com grandes empresas estrangeiras e nacionais, chamadas a aconselhar os organismos estatais de planificação" (SANTOS, 1994b:139).

No Brasil, vemos unificarem as estratégias do Plano Nacional de Desestatização (PND) com as estratégias do novo planejamento (gestão). As orientações ditadas pelas consultorias globais na preparação das regiões têm o intuito de atrair investimentos internacionais que, todavia, tendem a resultar no aprofundamento do uso hierárquico do território nacional. Outrossim, manifesta-se a sobreposição da politica das empresas sobre a política do Estado (SANTOS, 2000).

Como resultado, lembra Furtado (1992:35): “Em um país ainda em formação, como é o Brasil, a predominância da lógica das empresas transnacionais na ordenação das atividades econômicas conduzirá quase que necessariamente a tensões inter-regionais, à exacerbação de rivalidades corporativas e à formação de bolsões de miséria, tudo apontando para a inviabilização do país como projeto nacional". De fato, tendo em vista que o contexto apresentado em nossas pesquisas aponta para um aprofundamento do uso reticular e seletivo do território, torna-se um imperativo analisar o papel desempenhado pelos novos agentes e suas metodologias na apropriação e transformação do escopo do planejamento territorial.

Com vistas a compreender se as ações hoje empreendidas pelo atual governo federal se afastam ou se aproximam das relações anteriormente relatadas, entendemos que este artigo contribui para um estudo da dinâmica do "novo" planejamento, fruto das pretensões da Constituição de 1988.

O PLANEJAMENTO TERRITORIAL NO BRASIL NOS ANOS 1990: AS AÇÕES DAS EMPRESAS GLOBAIS DE CONSULTORIA (O CASO DA BOOZ-ALLEN \& HAMILTON)

Resumo: Este artigo apresenta alguns resultados de nossas pesquisas. Procuramos analisar as empresas globais de consultoria como importantes atores do alargamento dos contextos da globalização no território brasileiro. Nos anos 1990, tais empresas ampliaram seus laços de 
cooperação com o Estado, legitimando, entre outras ações, uma nova concepção de planejamento territorial para viabilizar a denominada integração competitiva entre as regiões. Destacamos, nesse contexto, as ações da empresa Booz-Allen \& Hamilton junto ao governo federal na condição de um dos agentes responsáveis pelo novo planejamento territorial brasileiro, com participação na concepção dos Planos Plurianuais (PPAs), especialmente o Programa “Avança Brasil” (2000-2003).

Palavras-chave: uso do território brasileiro; globalização; informação; empresas de consultoria; planejamento territorial.

TERRITORIAL PLANNING IN BRAZIL IN THE NINETIES: THE ACTIONS OF GLOBAL CONSULTING COMPANIES (THE BOOZ-ALLEN \& HAMILTON CASE)

Abstract: This article represents some of the results of the authors' research. The aim of the research was to analyze global consultancy companies who were important participants in the expansion of globalization in the Brazilian territory. These companies increased their ties of cooperation with the government in the 90's, emphasizing, among other actions, a new territorial planning concept to make the so-called competitive integration among regions viable. The actions of Booz-Allen \& Hamilton, together with the Federal government, responsible for the new Brazilian territorial planning with participation from the Pluriannual Plans (PAP), especially the "Avança Brasil" program (2000-2003), have been highlighted in this context.

Keywords: use of Brazilian territory; globalization; information; consultancy companies; territorial planning.

\section{BIBLIOGRAFIA}

ABLAS, L. (2003). O "Estudo dos Eixos" como instrumento de planejamento regional. In: GONÇALVES, M. F.; BRANDÃO, C. A.; GALVÃO, A. C. F. (Org.). Regiões e cidades, cidades nas regiões: o desafio urbano-regional. São Paulo: Ed. Unesp/Anpur.

ARAÚJO, T. B. (2000). Ensaios sobre o desenvolvimento brasileiro: heranças e urgências. Rio de Janeiro: Revan/Fase.

BECKER, B. (1991). Modernidade e gestão do território no Brasil: da integração nacional à integração competitiva. Espaço \& Debates, n. 32, p. 47-56. 
BORDELEAU, Y. (1986). La fonction de conseil auprès des organisations. Paris: Chotard et Associés Editeurs.

BRASIL (1999). Constituição da República Federativa do Brasil: promulgada em 5 de outubro de 1988. 22. ed. São Paulo: Saraiva.

CHAUI, M. de S. (1982). Cultura e democracia: o discurso competente e outras falas. 3. ed. São Paulo: Moderna.

CONSÓRCIO BRASILIANA (2000). Identificação de Oportunidades de Investimentos Públicos elou Privados. Estudo dos Eixos Nacionais de Integração e Desenvolvimento. Relatório Síntese, Tomo I. Brasília: Ministério do Planejamento, Orçamento e Gestão.

CORRÊA, R. L. (1997). Trajetórias geográficas. Rio de Janeiro: Bertrand Brasil.

DONADONE, J. C. (2001). “Os hunos já chegaram!”: dinâmica organizacional, difusão e conceitos gerenciais e a atuação das consultorias. Tese (Doutorado) - Escola Politécnica, USP.

FERES, F. L. C. (2002). A questão regional nos Planos Plurianuais recentes no Brasil. In: KON, A. (Org.). Unidade e fragmentação: a questão regional no Brasil. São Paulo: Perspectiva.

FURTADO, C. (1992). A construção interrompida. Rio de Janeiro: Paz e Terra.

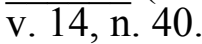

(2000). O fator político na formação nacional. Estudos Avançados,

GALLOUJ, F. (1994). Les déterminants de l'innovation dans les activités de Conseil. Revue Française du Marketing, n. 149, p. 33-51.

GALVÃO, A. C. F.; BRANDÃO, C. A. (2003). Fundamentos, motivações e limitações da proposta dos "Eixos Nacionais de Desenvolvimento". In: GONÇÁLVES, M. F; BRANDÃO, C. A.; GALVÃO, A. C. F. (Org.). Regiões e cidades, cidades nas regiões: o desafio urbano-regional. São Paulo: Ed. Unesp/Anpur.

GARCIA, R. C. (2000). A reorganização do processo de planejamento do governo federal: O PPA 2000-2003. Brasília: Ipea.

GOE, R. W. (1996). An examination of relationship between corporate spatial organization, restructuring and external contacting of producer services within a metropolitan region. Urban Affairs, v. 32, n. 1, p. 23-45, set.

IANNI, O. A. (2000). Globalização e o retorno da questão nacional. Primeira Versão, Campinas, IFCH-Unicamp. 
KARPIK, L. (1978). Organizations, institutions and history. In: KARPIK, L. (Ed.). Organization and environment. Londres: Sage, p. 15-68.

LOJKINE, J. (1995). A revolução informacional. Trad. J. Paulo Neto. São Paulo: Cortez.

MENESES, M. P. (2004). Agentes do conhecimento? A consultoria e a produção do conhecimento em Moçambique. In: SANTOS, B. de S. (Org.). Conhecimento prudente para uma vida decente: um discurso sobre as ciências revisitado. São Paulo: Cortez.

MOSTAFA, S. P. (1994). As ciências da informação. São Paulo em Perspectiva, Fundação Seade, v. 8, n. 4, out./dez.

PERROUX, F. (1967). A economia do século XX. Lisboa: Livraria Moraes Editora.

RAFFESTIN, C. (1993). Por uma geografia do poder. São Paulo: Ática. RIBEIRO, A. C. T. (2000). Mudanças culturais e a ação estimulada pela técnica. In: SOUZA, A. et al. (Org.). Milton Santos: cidadania e globalização. Bauru: Saraiva.

SANTOS, B. de S. (1989). Introdução a uma ciência pós-moderna. Rio de Janeiro: Graal.

(1994a). Técnica, espaço, tempo: globalização e meio técnico-

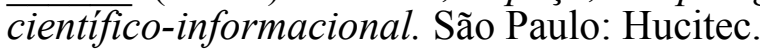

$\overline{\text { Hucitec. }}$.

(1994b). Por uma economia política da cidade. São Paulo:

(1994c). O retorno do território. In: SANTOS, M. et al. (Org.). Território: globalização e fragmentação. São Paulo: Hucitec/Anpur.

(1996). A natureza do espaço: espaço e tempo, razão e emoção. São Paulo: Hucitec.

(2000). Por uma outra globalização: do pensamento único à consciência universal. Rio de Janeiro: Record.

(2002). O país distorcido: o Brasil, a globalização e a cidadania. São Paulo: Publifolha.

Paulo: Edusp.

(2003 [1979]). Economia espacial: críticas e alternativas. São

(2004 [1979]). O espaço dividido: os dois circuitos da economia $\overline{\text { urbana }}$ dos países subdesenvolvidos. Trad. M. T. R. Viana. 2. ed. São Paulo: Edusp.

SANTOS, M.; SILVEIRA, M. L. (2001). O Brasil: território e sociedade no início do século XXI. Rio de Janeiro: Record. 
SILVA, A. M. B. da (2001). A nova divisão territorial do trabalho brasileira e a produção de informações na cidade de São Paulo (as empresas de consultoria). In: SANTOS, M.; SILVEIRA, M. L. O Brasil: território e sociedade no início do século XXI. Rio de Janeiro: Record.

(2002). A contemporaneidade de São Paulo: produção de

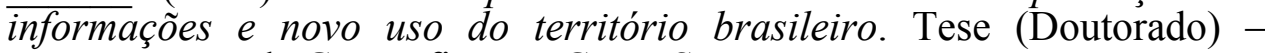
Departamento de Geografia, FFLCH, USP.

SILVEIRA, M. L. (1997). Concretude territorial, regulação e densidade normativa. Revista Experimental, Laboplan-USP, ano II, n. 2, p. 35-45.

(1999). Um país, uma região: fim de século e modernidades na Argentina. São Paulo: Fapesp/Laboplan-USP.

STERN, P.; TUTOY, P. (1995). Le métier de consultant: principes, méthodes, outils. 3. tir. Paris: Les Éditions d'Organisation.

VELTZ, P. (1997). Mondialisation, villes et territoires: l'économie d'archipel. Paris: Presses Universitaires.

WOOD, P. A. (1996). Business services, the management of change and regional development in the UK. Transactions of the Institute of British Geographers, v. 21, p. 644-665. 